\title{
Dramatic effect of pop-up satellite tags on eel swimming
}

\author{
Erik Burgerhout • Ryotaro Manabe - Sebastiaan A. Brittijn • Jun Aoyama • \\ Katsumi Tsukamoto • Guido E. E. J. M. van den Thillart
}

Received: 16 February 2011 /Revised: 30 April 2011 / Accepted: 3 May 2011 / Published online: 19 May 2011

(C) The Author(s) 2011. This article is published with open access at Springerlink.com

\begin{abstract}
The journey of the European eel to the spawning area in the Sargasso Sea is still a mystery. Several trials have been carried out to follow migrating eels with pop-up satellite tags (PSATs), without much success. As eels are very efficient swimmers, tags likely interfere with their high swimming efficiency. Here we report a more than twofold increase in swimming cost caused by a regular small satellite tag. The impact was determined at a range of swimming speeds with and without tag in a 2-m swimming tunnel. These results help to explain why the previous use of PSATs to identify spawning sites in the Sargasso Sea was thus far unsuccessful.
\end{abstract}

Keywords Anguilla anguilla $\cdot$ Migration · Satellite tracking · Swimming · Cost of transport · Sargasso Sea

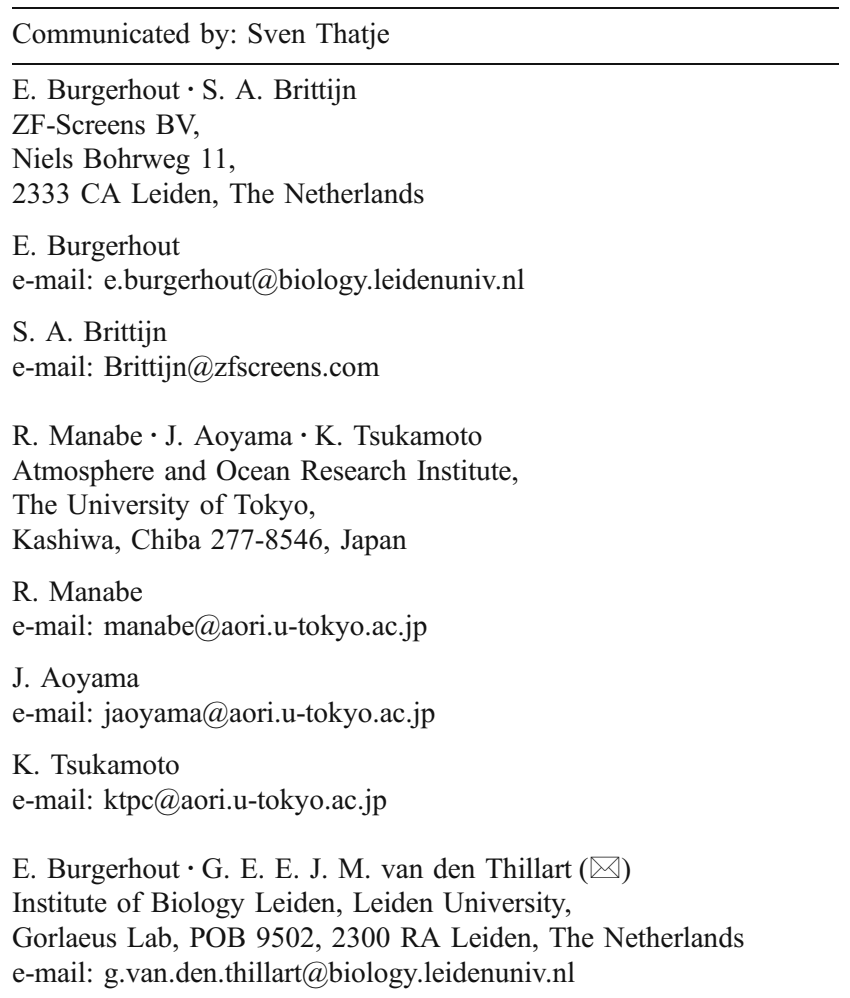

\section{Introduction}

For decades, tracking studies with eels have been conducted to reveal the oceanic migration routes to their mysterious spawning areas - $6,000 \mathrm{~km}$ from the European coast-by using acoustic and archival tags (Tesch 2003). Recently, the use of pop-up satellite tags (PSATs), developed for tracking large animals $(>50 \mathrm{~kg})$, were used in several studies for tracking eels (Aarestrup et al. 2009; Jellyman and Tsukamoto 2002). Although the oceanic migration routes were partially obtained this way, the assumed spawning areas have never been reached. Results showed a much lower travel speed than required for reaching the spawning areas in time. The minimal speed for European silver eels is $0.4 \mathrm{~ms}^{-1}, \sim 6,000 \mathrm{~km}$ within 6 months - the time between leaving the coast and the occurrence of the first larvae (Tesch 2003). In contrast, Aarestrup et al. (2009) found an average horizontal migration speed of $13.8 \mathrm{~km}^{-1}$ day $^{-1}$, which corresponds to ca. $0.16 \mathrm{~ms}^{-1}$, obviously far too slow. The authors stated that this low speed mainly reflected the drag of the PSAT.

The effect of PSATs on the swimming efficiency and swimming behaviour of eels has not been tested before. Eels have been shown to be very efficient swimmers; they are some five times more efficient than salmonids with respect to the energy cost of swimming (van Ginneken and van den Thillart 2000; van den Thillart et al. 2004; Palstra and van den Thillart 2010). Particularly this extreme high swimming efficiency must have been a strong selection force during evolution; as a consequence, any interference with shape and movement must have a serious impact on the cost of transport (COT) and thus interferes with successful spawning migration. Current PSATs have almost the same cross section as that of an eel of $1 \mathrm{~kg}$, which therefore almost doubles the hydrodynamic drag. The PSAT resists not only forward but also sideward motion, which must have an additional disturbing effect on the anguilliform mode of swimming. Furthermore due to the positive buoyancy of the PSAT, there 
will be an additional constant pull upwards, which also impairs the swimming mode. Thus, one may expect a strong interference of a PSAT with swimming mode, swimming capacity and swimming efficiency. In this study we tested the effect of a small PSAT on the swimming efficiency of female European eels of about $1 \mathrm{~kg}$.

\section{Materials and methods}

Swim performance tests (trial 1-5) were carried out in 127-L Blazka-type swimming tunnels (van den Thillart et al. 2004) with running natural seawater (35 ppt) at $18 \pm 1^{\circ} \mathrm{C}$ under red light according to the speed test protocol of Palstra et al. (2008). Five different trials were performed on each of eight farmed female silver eels $(1,026 \pm 31 \mathrm{~g} ; 76.5 \pm 1.0 \mathrm{~cm})$. Every trial included a 1-day swim performance test (speed test) after appropriate conditioning. The trials were performed in the following order: (1) no tag (control); (2) no tag, after operation (to check the effect of the operation); (3) positive buoyant tag; (4) neutral buoyant tag; (5) no tag, after removal of the tag (to test handling and training effects). The protocols are summarized in Table 1. The 1-day speed test was carried out in five steps from 0.4 to $0.8 \mathrm{~ms}^{-1}$ with increments of $0.1 \mathrm{~ms}^{-1}$ at 2 -h intervals. The optimal swimming speed — speed with lowest COT—is within this

Table 1 Protocol swim performance test

\begin{tabular}{ll}
\hline Day & Action \\
\hline 1 & Adaptation; overnight at $0.4 \mathrm{~ms}^{-1}$ \\
2 & Trial 1: no tag, before operation - speed test; \\
& overnight at $0.4 \mathrm{~ms}^{-1}$ \\
$3+4$ & Operation, attach base; 2 days at $0.4 \mathrm{~ms}^{-1}$ \\
5 & Trial 2: no tag, after operation-speed test; \\
& overnight at $0.4 \mathrm{~ms}^{-1}$ \\
6 & PSAT attached; overnight at $0.3 \mathrm{~ms}^{-1}$ \\
7 & Trial 3: positive buoyant tag-speed test; \\
& overnight at $0.3 \mathrm{~ms}^{-1}$ \\
8 & Added metal weight to tag; overnight at $0.3 \mathrm{~ms}^{-1}$ \\
9 & Trial 4: neutral buoyant tag-speed test; \\
& overnight at $0.3 \mathrm{~ms}^{-1}$ \\
10 & Tag removed; overnight at $0.4 \mathrm{~ms}^{-1}$ \\
11 & Trial 5: no tag, final test - speed test; end
\end{tabular}

Speed test includes five 2-h intervals $0.4-0.8 \mathrm{~ms}^{-1}$ in steps of $0.1 \mathrm{~ms}^{-1}$. After the last step, the eels were kept at $0.1 \mathrm{~ms}^{-1}$ for $1.5 \mathrm{~h}$ to measure the resting rate. The oxygen consumption was measured over the first $90 \mathrm{~min}$ of the interval; thereafter, the tunnel was flushed for $30 \mathrm{~min}$ to restore the oxygen level. Before introduction to the tunnels and before the operation, the eels were anaesthetized with $1 \mathrm{~mL} \mathrm{~L}^{-1}$ clove oil solution ( $10 \%$ clove oil dissolved in $96 \%$ ethanol) range of speeds, as demonstrated in a previous study (Palstra et al. 2008). The oxygen consumption was measured during the first 90 min of each interval. It was calculated from the decline of the oxygen concentration in the closed swimming tunnel. The oxygen levels were kept between $95 \%$ and $75 \%$ air saturation. To restore the initial saturation level, the swimming tunnel was flushed with air-saturated water during the last $30 \mathrm{~min}$ of each interval. The swimming tunnels were calibrated with a Doppler flow technique to determine the correct water flow in the tunnel (van den Thillart et al. 2004).

The eels were introduced in the tunnels 1 day before each trial, and left overnight while swimming at $0.4 \mathrm{~ms}^{-1}$. After trial 1 , a $20 \times 9$-mm Teflon plate $(1.5 \mathrm{~mm}$ thick) was placed under the skin of the experimental animal about $30 \mathrm{~mm}$ in front of the dorsal fin, the same location as used by Jellyman and Tsukamoto (2002). A slightly different attachment was used to prevent perforation of the swimming muscles. A silk line was pulled through the plate and skin on either side; the line was left outside the body. After the operation, the eels were placed back into the swimming tunnels and swam for 2 days at $0.4 \mathrm{~ms}^{-1}$. Trial 2 was carried out 2 days after the operation. Thereafter a PSAT was attached to the Teflon plate, leaving about $20 \mathrm{~mm}$ between the fish and the tag. The eels were placed back in the tunnel and left swimming overnight at $0.3 \mathrm{~ms}^{-1}$. The lower speed was necessary, as the eels could not swim faster overnight with a PSAT attached. At the end of trial 3, a small metal weight ( $10.9 \mathrm{~g}$ ) was added to the tag to create neutral buoyancy. The eels were placed back in the tunnel and left swimming overnight at $0.3 \mathrm{~ms}^{-1}$. After trial 4 the PSAT was removed and the eels were introduced in the tunnel and left overnight swimming at $0.4 \mathrm{~ms}^{-1}$. The last trial (5) was carried out to control whether the handling and previous swim tests changed the swim performance. At the end of each trial, the speed was set at $0.1 \mathrm{~ms}^{-1}$ for $1.5 \mathrm{~h}$ to measure resting conditions. This low speed was necessary to keep the water well mixed, while low enough for the eels to stay at rest. The optimal swimming speed (COT) and critical swimming speed were calculated according to Brett (1964). According to this method, the swimming speed is increased in intervals of $>30 \mathrm{~min}$, in $8-10$ equal steps up to collapse; the critical speed is then interpolated from the last two speeds.

Results were statistically tested using repeated measures ANOVA. Dimensions of the PSAT were: body length $115 \mathrm{~mm}$, diameter first part $20 \mathrm{~mm}$, diameter second part non-functional $40 \mathrm{~mm}$, length of antenna $170 \mathrm{~mm}$ and weight in air $53 \mathrm{~g}$. The used tags were not functional but corresponded in size and buoyancy with miniPAT from Wildlife Computers. The experiments were carried out according to the Dutch law on animal experimentation with approval \#DEC-10089. 


\section{Results and discussion}

In this study, female silver eels swam at $0.1-0.8 \mathrm{~ms}^{-1}$, with and without a PSAT. The swimming performance was tested with the 1-day speed test at five different conditions (Table 1). There were no significant differences in oxygen consumption rates (at all speeds) between the conditions without tag; i.e. trials 1, 2, 5 (Fig. 1a, $P>0.05$ ). Therefore, we can infer that there was no negative effect of the operation on the swimming efficiency of the eels. Thus the results of trial 1, 2 and 5 can be considered as controls. In contrast, when a PSAT was attached to the eels (trials 3 and 4), the oxygen consumption during swimming was more than twofold higher compared to the control groups $(P<0.001$, Fig. 1a). Even when the PSAT was made neutrally buoyant (trial 4 ), the oxygen consumption during
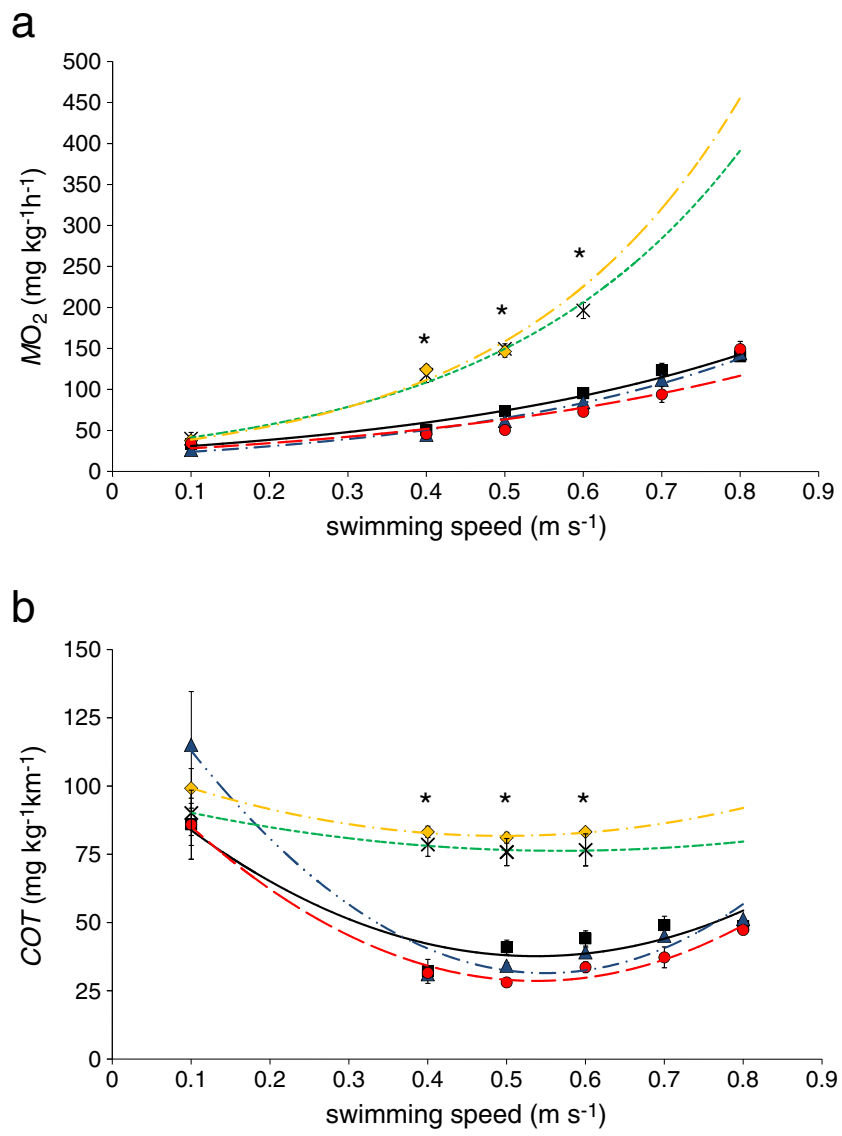

Fig. 1 Effect of pop-up satellite tags on a oxygen consumption (in milligram $\mathrm{O}_{2}$ per kilogram per hour) and $\mathbf{b}$ cost of transport (in milligram $\mathrm{O}_{2}$ per kilogram per kilometer) for swimming $1 \mathrm{~kg}$ European eels $(n=8)$. Treatment levels were: no tag, before operation (filled square, black); no tag, after operation (filled triangle, blue), with positive buoyant tag (multiplication sign, green); with neutral buoyant tag (filled diamond, orange); no tag, final test (filled circle, red). All data are mean \pm SE. Data were compared using repeated measures ANOVA. Asterisk indicates significant difference from control at $P<0.05$ swimming was still ca. twofold higher than the control $(P<0.001)$. As there were no significant differences found between the positive vs the neutrally buoyant PSAT $(P>0.05)$, the results suggests that the drag more than the lift of the PSAT may have been the most crucial factor impairing swimming performance. Although, the vertical migration as observed for eels in the wild (Aarestrup et al. 2009) could not be simulated during this study.

Also the COT was significantly higher when eels were swimming with a PSAT $(P<0.001$, Fig. $1 b)$, i.e. a change from 25 to $75 \mathrm{mg} \mathrm{O}_{2} \mathrm{~kg}^{-1} \mathrm{~h}^{-1}$. Eels with a PSAT showed irregular swimming at $0.5 \mathrm{~ms}^{-1}$ and fatigued after a few minutes when the speed was raised to $0.6 \mathrm{~ms}^{-1}$. As eels have a very regular swimming mode with a nearly constant wave frequency, irregular swimming was immediately visible. The calculated critical swimming speed with a PSAT was significantly lower compared to the control groups; i.e. $0.48 \pm 0.02$ and $0.73 \pm 0.02 \mathrm{~ms}^{-1}$ respectively $(P<0.001)$. In contrast, during the trials without PSAT, all eels were able to swim up to $0.8 \mathrm{~ms}^{-1}$. The results of trials 1,2 , and 5 (without PSAT) were comparable to those published recently (Palstra et al. 2008).

In a recent study, Steinhausen et al (2006) observed that an external tag increased the oxygen consumption of cod at high swimming speeds, while optimal and critical swimming speeds were significantly decreased. In our study, with the much bigger PSAT, we observed severely impaired swimming already at low speeds. The difference between the two studies may be due to the different mode of swimming, i.e. subcarangiform vs anguilliform, but more likely due to the rather large difference in extra drag (corresponding to the cross section surface of the tag, i.e. 2 vs $\sim 13 \mathrm{~cm}^{2}$ respectively). Although tag technology is advancing, tags show negative effects in several studies on swimming performance, survival, behaviour and growth rates (Bridger and Booth 2003; Makiguchi and Ueda 2009). Negative effects of external tags on swimming performance are also found in other animals like penguins (Saraux et al. 2011) and seals (Hazekamp et al. 2010). This clearly calls for further improvement of the current tags.

In conclusion, our results show a dramatic effect of the smallest available PSAT on the swimming efficiency of European eels: a more than twofold higher oxygen consumption at all tested cruising speeds and a severely reduced swimming performance. Hence, smaller PSATs with much less interference on swimming performance are required to unravel the still mysterious journey to the spawning areas of European eels.

Acknowledgements This study was supported by the Dutch Ministry of Economic Affairs, Agriculture and Innovation (grant \# VISS/1447/2408008) and by the Japanese Agriculture, Forestry and Fisheries Research Council. We would like to thank Christian Tudorache for his help with the figures and statistics. 
Open Access This article is distributed under the terms of the Creative Commons Attribution Noncommercial License which permits any noncommercial use, distribution, and reproduction in any medium, provided the original author(s) and source are credited.

\section{References}

Aarestrup K, Økland F, Hansen MM, Righton D, Gargan P, Castonguay M, Bernatchez L, Howey P, Sparholt H, Pedersen MI, McKinley RS (2009) Oceanic spawning migration of the European eel (Anguilla anguilla). Science 325:1660

Brett JR (1964) The respiratory metabolism and swimming performance of young sockeye salmon. J Fish Res Board Can 21:11831226

Bridger CJ, Booth RK (2003) The effects of biotelemetry transmitter presence and attachment procedures on fish physiology and behaviour. Rev Fish Sci 11:13-34

Hazekamp AAH, Mayer R, Osinga N (2010) Flow simulation along a seal: the impact of an external device. Eur J Wildl Res 56:131140

Jellyman D, Tsukamoto K (2002) First use of archival transmitters to track migrating freshwater eels Anguilla dieffenbachii at sea. Mar Ecol Prog Ser 233:207-215
Makiguchi Y, Ueda H (2009) Effects of external and surgically implanted dummy radio transmitters on mortality, swimming performance and physiological status of juvenile masu salmon Oncorhynchus masou. J Fish Biol 74:304-311

Palstra AP, van den Thillart GEEJM (2010) Swimming physiology of European silver eels (Anguilla anguilla L.): energetic costs and effects on sexual maturation and reproduction. Fish Physiol Biochem 36:297-322

Palstra A, van Ginneken V, van den Thillart G (2008) Cost of transport and optimal swimming speed in farmed and wild European silver eels (Anguilla anguilla). Comp Biochem Physiol Mol Integr Physiol 151:37-44

Saraux C, Le Bohec C, Durant JM, Viblanc VA, Gauthier-Clerc M, Beaune D, Park Y-H, Yoccoz NG, Stenseth NC, Le Maho Y (2011) Reliability of flipper-banded penguins as indicators of climate change. Nature 469:203-206

Steinhausen MF, Andersen NG, Steffensen JF (2006) The effect of external dummy transmitters on oxygen consumption and performance of swimming Atlantic cod. J Fish Biol 69:951-956

Tesch F (2003) The eel. Blackwell, Oxford

van den Thillart G, van Ginneken V, Körner F, Heijmans R, van der Linden R, Gluvers A (2004) Endurance swimming of the European eel. J Fish Biol 65:1-7

van Ginneken VJT, van den Thillart GEEJM (2000) Eel fat stores are enough to reach the Sargasso. Nature 403:156-157 